Med Arh. 2015 Apr; 69(2): 130-132 Received: January 15th 2015 | Accepted: March 25th 2015

\title{
Pancreatic Injury in Blunt Abdominal Trauma
}

\author{
Jasmin Hasanovic, Mirha Agic, Zijah Rifatbegovic, Zlatan Mehmedovic, Amra Jakubovic-Cickusic \\ Clinic for Surgery, University Clinical Center Tuzla, Tuzla, Bosnia and Herzegovina
}

Corresponding author: Jasmin Hasanovic, MD. Department of Surgery, University Clinical Center Tuzla, Tuzla, Bosnia and Herzegovina. Phone: +387 61743 347; E-mail: jasmin.hasanovic@hotmail.com

\begin{abstract}
Introduction: Pancreatic injuries are not common after blunt and penetrating trauma, but can be challenging to diagnose and manage. Case report: Twenty-three year old man, injured during a fall from a motorcycle two days earlier, was admitted to Department of Surgery, University Clinical Centre Tuzla because of suspicion of pancreatic trauma. Immediately after hospitalization, patient underwent laboratory and radiological tests that revealed the existence of pancreatic trauma, so we opted for urgent surgical treatment. Surgery and early postoperative course were normal and the patient was discharged on the ninth postoperative day. Conclusion: Proper diagnosis and well-selected surgical treatment significantly increases the chances for recovery of these patients.
\end{abstract}

Keywords: pancreatic injury, blunt trauma.

\section{INTRODUCTION}

Pancreatic injuries are uncommon and can result from direct penetration into the organ or through the transmission of blunt force energy to the retroperitoneum. Some studies report an incidence of $0.2 \%$ cases for blunt trauma up to $1.1 \%$ cases for penetrating trauma (1). Despite of low frequency of these injuries they are associated with significant morbidity and mortality, resulting in mortality rates of $23.4 \%$ and $30.2 \%$ for blunt and penetrating trauma, respectively (2). There are several different classification systems of pancreatic injuries. The most commonly used system is the one devised by the American Association for the Surgery of Trauma (Table 1) which is based on anatomic location of injury and status of pancreatic duct (3). The diagnosis of pancreatic injuries is made by clinical examination, laboratory tests and imaging techniques such as ultrasound of the abdomen, contrast-enhanced CT scan, RECAP, or MCPC. The basic approach in the treatment of pancreatic injury is surgical and the choice of surgical procedure is govern by the location and the grade of injury.

\section{CASE REPORT}

Twenty-three year old man was hospitalized in General Hospital Tesanj due to injuries he sustained in motorcycle accident. On admission the patient was haemodynamically and respiratory stable with Glasgow Coma Score 12. Small laceration on face was surgically debrided and sutured. During physical examination there were no visible signs of trauma of the chest, abdomen and extremi- ties. Findings on CT scan of the brain, cervical spine and abdomen (without contrast enhancement) didn't suggest existence of any major injury. Since the conducted diagnostic evaluation didn't verify the existence of traumatic changes, the patient was treated conservatively. However, two days after admission, his clinical status started to deteriorate. In order to evaluate the patient's status, control contrast-enhanced abdominal CT scan was made which suggested suspicion of a possible pancreatic injury. After that, patient was referred to University Clinical Center Tuzla for further diagnostic and therapeutic evaluation.

\begin{tabular}{lll}
\hline Grade & $\begin{array}{l}\text { Type of } \\
\text { injury }\end{array}$ & Description of injury \\
\hline I & Hematoma & $\begin{array}{l}\text { Minor contusion without duct injury } \\
\text { or tissue loss }\end{array}$ \\
\hline Laceration & $\begin{array}{l}\text { Superficial laceration without duct } \\
\text { injury or tissue loss }\end{array}$ \\
\hline II & Hematoma & $\begin{array}{l}\text { Major contusion without duct injury or } \\
\text { tissue loss }\end{array}$ \\
\hline III & Laceration & $\begin{array}{l}\text { Distal transection or parenchymal } \\
\text { injury with duct injury }\end{array}$ \\
\hline IV & Laceration & $\begin{array}{l}\text { Proximal* transection or parenchymal } \\
\text { injury involving ampulla }\end{array}$ \\
\hline V & Laceration & \begin{tabular}{l} 
Massive disruption of pancreatic head \\
\hline
\end{tabular}
\end{tabular}

Table 1. American Association for the Surgery of Trauma: Pancreas organ injury scale. ${ }^{*}$ Proximal pancreatic injuries are injuries to the patient's right of the superior mesenteric vein 


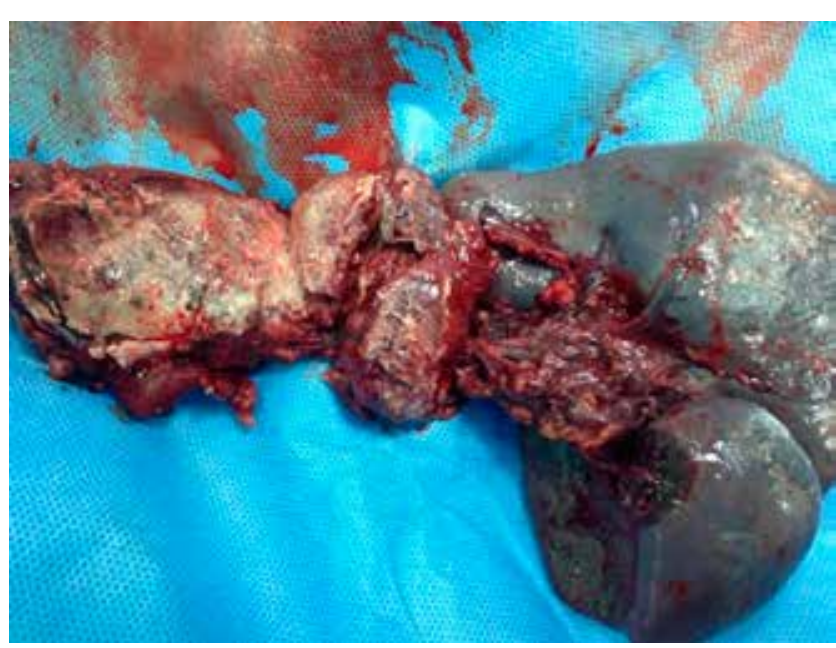

Figure 1. "En Bloc" resected distal pancreas and spleen

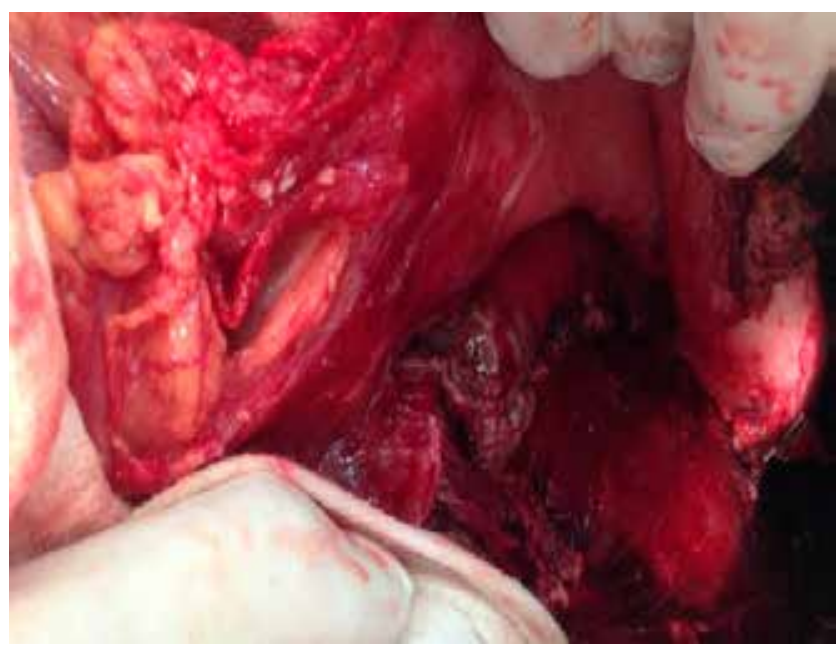

Figure 2. Remaining pancreas after distal pancreatectomy

On admission to our hospital, the patient was haemodynamically and respiratory stable. Physical examination revealed abdominal tenderness with signs of diffuse peritonitis. During preoperative evaluation laboratory tests and contrast-enhanced CT scan of the abdomen were made. Laboratory tests showed the elevation of leukocytes (17.42, reference values 4.40 to 11.60 ), C-reactive protein (180.5, reference values 0.0 to 3.3 ) and mild elevation of serum amylase (618 U/L, reference values 23 to 135$)$. Contrast-enhanced CT scan of the abdomen showed the presence of larger amounts of free fluid in the abdomen, and voluminous, inhomogeneous pancreas, transected at the body. CT scan also recorded laceration of the spleen, as well as diffuse imbibitions of adipose tissue and edema in the gastrocolic ligament (contusion). Given the clinical findings and the results of diagnostic evaluation, we decided for urgent surgical treatment.

During surgery we found larger amount of free serohemoragic fluid inside the abdominal cavity, as well as incomplete transection of pancreas with disruption of the main duct to the patient's left of the superior mesenteric vein. According to AAST organ injury scale it was grade III injury of the pancreas. We also found traumatic laceration in the lower third of the spleen. These intraoperative findings were consistent with CT scan we did during preoperative evaluation. With regard to intraoperative findings, we decided for distal pancreatectomy and splenectomy with external drainage (Figure 1,2).

After surgery, the patient was admitted to the intensive care unit. The first postoperative day we started with oral nutrition of patient. The second postoperative day, the patient was haemodynamically and respiratory stable, moved from intensive care unit to the Department of Hepatobilliary and pancreatic surgery. Further postoperative course was normal, without any complications. On the eight postoperative day, the drains were removed and the patient was, on the next day, discharged home for outpatient follow-up.

\section{DISCUSSION}

Pancreatic injuries are relatively uncommon but, nevertheless, represent serious problem because of high morbidity and mortality rates that accompany them, with morbidity rates ranging between $45 \%$ and $60 \%$, and mortality rates ranging between $23.4 \%$ and $30.2 \%(2,4)$. The reason for these high morbidity and mortality rates can be attributed to delays in diagnosis and, consecutively, treatment. Pancreatic enzymes are well known for their caustic nature, so every delay in management of pancreatic injuries results in massive systemic inflammation with subsequent poor outcomes.

Establishing the presence of pancreatic injury is a considerable challenge, as no single imaging modality has been found to highly effective. Therefore, for early and timely diagnosis of pancreatic injury, a high index of suspicion must be maintained. Patients with a history of acceleration/deceleration injury, forceful anterior compression of the abdomen and lower thoracic and upper lumbar vertebra fractures are at increased risk for pancreatic injury. A seatbelt sign across the upper and middle abdomen should suggest the possibility of serious intraabdominal injury (5). In our case, the patient sustained pancreatic injury as a result of an impact of handlebars on the upper part of the abdomen. Because of the retroperitoneal location of pancreas, physical examination findings may be limited. Sometimes, abdominal pain and peritoneal signs take days to develop, which can be observed in our case, where more than 24 hours passed before abdominal pain and peritoneal signs developed.

Routine laboratory tests can be helpful. Patients with elevations in white blood cell count, serum amylase, or lipase require further investigation. Recent studies report that elevated serum amylase and lipase levels, obtained 6 hours after trauma, can be used as reliable indicator of pancreatic injury, although non diagnostic within 6 hours or less after trauma (6).If the abdominal examination initially yields equivocal or unreliable results in a haemodynamically stable patient with hyperamylasemia, a contrast enhanced abdominal CT scan should be done. Although it can indicate pancreatic injury, CT scan is only moderately sensitive and can underestimate or miss pancreatic injury. The sensitivity for detecting parenchymal or ductal injury ranges between $60 \%$ and $68 \%(7,8)$. Abdominal CT scan is unreliable in diagnosing pancreatic duct injury and should not be used to guide therapy (9). For those patients endoscopic retrograde cholangiopancreatography may be helpful, as it is the best modality for imaging the pancreat- 
ic duct, and can be used as therapeutic procedure to stent lacerated ducts in selected patients $(10,11)$.

The management of pancreatic injuries is determined by the grade and location of injury. Minor pancreatic injuries (grade I) in haemodynamically stable patients can be treated conservatively (12). However, the mainstream of therapy for pancreatic injuries is surgical. Full exposure of pancreas is required for thorough inspection and assessment of the damage. Minor pancreatic contusions, hematomas, and capsular lacerations (grade I), as well as lacerations of the pancreatic parenchyma without major duct disruption or tissue loss (grade II), are treated with hemostasis and adequate external drainage. Distal pancreatic injuries with disruption of the main pancreatic duct (grade III) are best treated with distal pancreatectomy. Injuries to the pancreatic head, grade IV and V are the most difficult to manage. Unstable patients may require initial damage control before later definitive surgery. In rare instances when the proximal duct is injured in the absence of concomitant duodenal/ampullary injury, extended distal (subtotal) pancreatectomy or Roux-en-Y pancreaticojejunostomy (tail-sparing) may be performed. Massive destruction of the pancreatic head, or combined pancreatic and duodenal injuries are best treated with pancreaticoduodenectomy $(13,14)$.

In our case, physical examination, laboratory tests and contrast-enhanced CT scan of the abdomen, suggested pancreatic injury with duct disruption, so we decided for urgent surgical treatment which resulted in full recovery of the patient.

\section{CONCLUSION}

Pancreatic injuries are not frequent, but they have an important place in the abdominal trauma considering the high level of morbidity and mortality that is associates with these injuries. The diagnosis of pancreatic injuries is not simple and requires a high index of suspicion. Delay of a timely diagnosis significantly reduces the chances of adequate treatment, thereby increasing the morbidity and mortality. The main stream of therapy for pancreatic injuries is surgical, and is determined by the grade and location of injury. Since the majority of the pancreatic injuries are milder grade, most of the surgical interventions end with an exploration and external drainage. However, in cases in which pancreatic laceration with main duct injury is documented, some of the surgical resection procedures are indicated, such as distal pancreatectomy (with or without splenectomy) or cephalic duodenopancreatectomy (trauma Whipple).

\section{CONFLICT OF INTEREST: NONE DECLARED}

\section{REFERENCES}

1. Akhrass R, Yaffe MB, Brandt CP, Reigle M, FallonWF, Jr., Malangoni MA. Pancreatic trauma: a ten-year multi-institutional experience. Am Surg.1997; 63: 598-604.

2. Marin RS, Meredith JW. Management of acute trauma.In: Townsend C, Beauchamp D, Evers M, Mattox KS, eds. Sabiston Textbook of Surgery: The Biological Basis of Modern Surgical Practice. Philadelphia. Elsevier-Saunders. 2012. 430-470.

3. Moore EE, Cogbill TH, Malangoni MA, Jurkovich GJ, Champion HR, Gennarelli TA, et al. Organ injury scaling, II: Pancreas, duodenum, small bowel, colon, and rectum. J Trauma. 1990; 30: 1427-1429.

4. Subramanian A, Dente CJ, Feliciano DV. The management of pancreatic trauma in the modern era. Surg Clin North Am. 2007; 87: 1515-1532.

5. Velmahos GC, Tatevossian R, Demetriades D. The "seat belt mark" sign: a call for increased vigilance among physicians treating victims of motor vehicle accidents. Am Surg. 1999; 65: 181-185.

6. Mahajan A, Kadavigere R, Sripathi S, Rodrigues GS, Rao VR, Koteshwar P.Utility of serum pancreatic enzyme levels in diagnosing blunt trauma to the pancreas: A prospective study with systematic review. Injury. 2014; 45(9): 1384-1393.

7. Phelan HA, Velmahos GC, Jurkovich GJ. An evaluation of multidetector computed tomography in detecting pancreatic injury: results of a multicenter AAST study. J Trauma. 2009; 66: 641-647.

8. Ilahi O, Bochicchio GV, Scalea TM.Efficacy of computed tomography in the diagnosis of pancreatic injury in adult blunt trauma patients: a single-institutional study. Am Surg. 2002; 68(8): 704-708.

9. Bradley EL, Young PR, Chang MC, Allen JE, Baker CC, Meredith W, et al. Diagnosis and initial management of blunt pancreatic trauma. Ann Surg. 1998; 227(6): 861-869.

10. Bhasin DK, Surinder SR, Rawal P. Endoscopic retrograde pancreatography in pancreatic trauma: need to break the mental barrier. J Gastroenterol Hepatol. 2009; 24: 720-728.

11. Vezakis A, Koutoulidis V, Fragulidis G, Polymeneas G, Polydorou A.Complete traumatic main pancreatic duct disruption treated endoscopically: a case report. J Med Case Rep. 2014; 8: 173.

12. Malgras B, Douard R, Siauve N, Wind P. Management of left pancreatic trauma. Am Surg. 2011; 77(1): 1-9.

13. Krige JE, Beningfield SJ, Nicol AJ, Navsaria P.The management of complex pancreatic injuries. S Afr J Surg. 2005; 43(3): 92-102.

14. Duchesne JC, Simms ER. Pancreatic and duodenal injuries and current surgical therapies. In: Cameron JL, Cameron AM, eds. Current Surgical Therapy. Philadelphia. Elsevier-Saunders. 2014. 1036-1041. 